Comparative Philosophy Volume 2, No. 2 (2011): 23-49

Open Access / ISSN 2151-6014

www.comparativephilosophy.org

\title{
THE FUTURE OF HUMANITY: HEIDEGGER, PERSONHOOD AND TECHNOLOGY
}

\author{
MAHON O'BRIEN
}

\begin{abstract}
This paper argues that a number of entrenched posthumanist positions are seriously flawed as a result of their dependence on a technical interpretive approach that creates more problems than it solves. During the course of our discussion we consider in particular the question of personhood. After all, until we can determine what it means to be a person we cannot really discuss what it means to improve a person. What kinds of enhancements would even constitute improvements? This in turn leads to an examination of the technical model of analysis and the recurring tendency to approach notions like personhood using this technical model. In looking to sketch a Heideggerian account of personhood, we are reaffirming what we take to be a Platonic skepticism concerning technical models of inquiry when it comes to certain subjects. Finally we examine the question as to whether the posthumanist looks to apply technology's benefits in ways that we have reflectively determined to be useful or desirable or whether it is technology itself (or to speak as Heidegger would - the "essence" of technology) which prompts many posthumanists to rely on an excessively reductionist view of the human being.
\end{abstract}

Keywords: Heidegger, posthumanism, technology, personhood, temporality

A significant number of Posthumanists ${ }^{1}$ advocate the techno-scientific enhancement of various human cognitive and physical capacities. Recent trends in posthumanist theory have witnessed the collective emergence, in particular, of a series of analytically oriented philosophers as part of the Future of Humanity Institute at

O'BRIEN, MAHON: IRCHSS Postdoctoral Research Fellow, School of Philosophy, University College Dublin, Ireland. Email: mahonobrien@gmail.com

${ }^{1}$ The term itself [posthumanism] would clearly have troubled Heidegger, and without getting ahead of ourselves, he would, no doubt, insist that the very term was another symptom of the unshakeable dominion of Gestell/Enframing. The term "posthumanism" is an umbrella term covering a series of related movements. The key arguments in this paper are aimed, predominantly, at the movement within posthumanist theory which is often referred to as "Transhumanism". At the forefront of that movement are a series of analytic scholars working at The Future of Humanity Institute at Oxford. However, since a number of our arguments can be thought to apply to other types of posthumanism, especially when it comes to the question of technology and "Enframing", we will use the term "posthumanism" rather than switching back and forth between posthumanism and transhumanism. 
Oxford. According to one of the most well known of these philosophers, some of the gravest problems that beleaguer us as human beings involve our shortcomings as physical and emotional creatures susceptible to unhappiness, senescence and death. These posthumanists are committed to finding, in short, a cure for the human condition. $^{2}$ And yet, the human condition, that is, what it means to be a human, more specifically, a human person, is precisely what they fail to address ${ }^{3}$ :

With continuing advances in science and technology, people are beginning to realize that some of the basic parameters of the human condition might be changed in the future. One important way in which the human condition could be changed is through the enhancement of basic human capacities. (Bostrom and Roache 2007, 1)

Some of the "basic parameters" that posthumanists have in mind here relate to our mortality while they advocate the extension of human lifespan indefinitely. In the same paper it is noted that

Were it not for aging, our risk of dying in any given year might be like that of somebody in their late teens or early twenties. Life expectancy would then be around 1,000 years....In other words, retarding senescence would enable us to grow older without aging. Instead of seeing our health peak within the first few decades of life before gradually declining, we could remain at our fittest and healthiest indefinitely. For many, this represents a wonderful opportunity to experience, learn, and achieve many things that are simply not possible given current human life expectancy. (Op.cit., 4)

This aspect of posthumanist theory, in particular, shall concern us in what follows. What the posthumanist routinely overlooks in their refutation of objections to their proposals is the question of where one's sense of personhood would come from were the temporal backdrop of our radical finitude to be omitted from our reckoning. In suggesting that there are aspects of the human condition that may well change at our current rate of technological progress, posthumanists fail to address the question as to what makes the human condition meaningful or worthwhile to begin with. At best, they pay lip service to the importance of our emotional well-being without acknowledging the role played by temporality in shaping our affective experience. In focusing on various aspects of human well-being, all of which are aspects of our emotional well-being in some shape or form, they fail to look at the temporal context within which affectivity occurs and look on the various aspects of being human in an atemporal vacuum. For instance, if someone suggests that part of what gives our lives meaning are the attempts to complete certain projects within a certain time-frame, the post-humanist suggests that if one were to exist indefinitely, one would simply have more time to complete more projects. This misses the point hopelessly; our various

\footnotetext{
${ }^{2}$ This condition, moreover, is all too often described in terms of an affliction to be treated rather than a gift to be celebrated.

${ }^{3}$ Some of the features of our condition which they wish to overcome are in fact constitutive of any conception of the human condition and concomitant account of personhood or human flourishing to begin with.
} 
projects are in significant part infused with meaning and urgency because of the fact that there are very distinct temporal limits to what we can achieve. That is not to say that a life without temporal limits cannot have meaning, but surely that is one of the things which needs to be looked at. That is, if the lives we currently lead are run through with a temporal character, then what we have to think about are not the specifics of particular enhancement technologies, as Bostrom and others recommend, rather what should concern us is the question as to where a non-temporal account of personhood would come from, or upon what it would be based. And, before we can even begin to address that question, more time needs to be devoted to the question of how temporality conditions any current conception of personhood we may have.

The analytic approach to the question of posthumanism then, though the analysts have yet to realize it, has run aground; they are at something of an interpretive impasse, one that was inevitable given some of their presuppositions. One of the most problematic of the posthumanist's presuppositions, one which we will concentrate on in this paper, is the belief that the notion of personhood is well established as part of the backdrop to their own recommendations concerning a series of improvements to human persons which will issue in a post-human person. By ignoring the inescapably temporal constitution of personhood/personal identity, however, the posthumanist leaves their recommendations for the improvement of human persons open to the charge of being arbitrary.

The general strategy in this paper is indebted to a certain theoretical skepticism (with respect to morality) clearly evident in a number of Plato's dialogues. Questions as to what it is to be virtuous or just or good remain those for which Plato seems to harbour the least theoretical confidence in the dialogues, at least when it comes to subjecting them to the theoretical or technical model of the exact sciences. We redeploy this Platonic skepticism then, arguing that the technical language of the exact sciences (which Plato undermines with respect to its effectiveness when it comes to ethics, for example) simply is not suited to many of the problems and dilemmas raised by the issue of posthumanism. This can be characterized then as an attempt to offer a deconstructive, continental response to a series of analytic arguments, since the advocates of contemporary posthumanist theory we are targeting (again, specifically in the transhumanist sense) operate self-consciously within the analytic tradition. That does not reflect any inveterate bias or preference for the continental over the analytic approach in general. ${ }^{4}$ Rather, in this instance, the deconstructive purgative of a continental critique unearths a major blind-spot in the analytic treatment of posthumanism. Our efforts here may issue in a kind of Platonic aporia; nevertheless, we should be understood as at least trying to assist future efforts to pick a path out of the theoretical morass which currently benights this debate by

\footnotetext{
${ }^{4}$ It would be disingenuous to suggest that my own philosophical background is straightforwardly neutral since my most significant work to date has been largely devoted to Heidegger interpretation. Notwithstanding, I would argue that my attitude is more inclusive than many of the hardliners on either side would countenance. The stand-off between the continental and analytic traditions is a rather unfortunate intellectual development while the champions around which these partisan adversaries rally are often not nearly so easily pigeon-holed!
} 
identifying some of the unhelpful theoretical detritus which may clutter such paths. If the posthumanist can absorb some of the criticisms we offer regarding their failure to recognize the temporal constitution of personhood and the problematic nature of contemporary conceptions of technology, they might yet be able to offer more reflective arguments against the backdrop of an intuitively plausible, reconsidered account of personhood.

There are a plethora of questions and considerations that the notion of posthumanity brings to the table that remind us of just how prescient Bernard Williams was in his conviction that returning to the work of the ancient Greeks might well be the only way we can begin to appreciate the depth and difficulty of certain contemporary philosophical problems:

This is not just the piety of philosophy toward its history. There is a special reason for it... The idea is certainly not that the demands of the modern world on ethical thought are no different from those of the ancient world. On the contrary, my conclusion is that the demands of the modern world on ethical thought are unprecedented, and the ideas of rationality embodied in most contemporary moral philosophy cannot meet them; but some extension of ancient thought, greatly modified, might be able to do so. (Williams 1993, v)

The very notion of "enhancement" involves significant presuppositions. When we speak of "improving" people, or making the kinds of improvements that might lead to a better person, we presuppose an account of personhood beyond the mere classification "homo sapiens". After all, being human on its own, in that sense, would appear to be a morally neutral notion; in the context of what is right and wrong - the ability to suffer or feel pain would seem to be more relevant. And the capacity to suffer is one shared by all kinds of non-human animals. The posthumanist might look to immediately forestall these kinds of reservations, and some indeed have, insisting that the fact that such notions (e.g. personhood) are difficult to nail down is no argument against the relevance of future humanity's enhancements being viewed from an ethical perspective every bit as much as the current human model. The problem for the posthumanist here is that that type of move issues in something of a pyrrhic victory. The fact that we may fail to offer a comprehensive, axiomatic definition of personhood, which Jane English (1975) famously described in another context as a "cluster concept", is not in fact a good reason for choosing any arbitrary cluster of concepts whatsoever! Moreover, if one grants as much but then attempts to come up with a viable definition, then one is back in philosophy's proverbial gutter of explanatory poverty trying to find a place to start. And of course, all too often, critics have looked to begin in the wrong places and with the wrong kind of language. So while we may concede that one needs to begin to appreciate that change is coming and that we are required to think about such change - arbitrary, makeshift foundations for evaluating change are no foundations at all. ${ }^{5}$ Plato's dialogues represent a salutary

\footnotetext{
${ }^{5}$ Nick Bostrom's Future of Humanity Institute professes to be the intellectual centre that will serve this important function. However, in the main, the arguments and findings that have emerged from the
} 
reminder of the perils of trying to transpose the theoretical/technical template of the more exact sciences onto questions which don't admit of that sort of treatment. ${ }^{6} \mathrm{We}$ routinely transpose the techne model of the exact sciences onto questions that do not have the same rationalist/idealist backdrop and we end up philosophically marooned. What is needed, however, is an entirely different approach, not variations on the technical one. And such an approach, I would submit, is part of what Heidegger is trying to pave the way for. Granted, Heidegger never sees himself as answering questions such as "what is virtue?", but he certainly can be credited with an attempt to undermine the ratio-technical approach to human life from the very beginning;

institute lack objectivity in that the dice are heavily loaded against critics of posthumanism. In paying the merest lip service to the concerns of critics of posthumanism and annihilating straw-man arguments, they routinely dodge the more serious philosophical problems that need to be addressed. Most problematic is the institute's failure to address the question as to what personhood itself entails. Moreover, Bostrom repeatedly points to the fact that the difficulties involved do not, of necessity, constitute an argument against the enhancements proposed by posthumanists: "In order to decide what changes in a person's mood or personality count as improvements, then, we must confront questions like: By what standard do we assess improvements or the reverse in cases where a person's mood or personality does not have a serious adverse effect on their life? Is it even plausible to claim that there could be such a standard? If so, what is the best guide to what the standard is and how it applies in a particular case: the opinion of the subject, the opinions of those who interact with the subject, or something else? The importance of addressing such questions does not entail that mood and personality enhancement is impossible or inadvisable; but a certain amount of philosophical reflection and analysis is required if we are to gain genuine benefits from such technology." (Bostrom and Roache 2007) The problem however is that, in the same paper for example, Bostrom and Roache proceed to describe various different types of enhancement individually in the context of a rather nebulous, undefined notion of human flourishing without ever actually offering any account of what it means to be a person such that we could begin to see what it might mean to improve such a person what it would be for a person to flourish in the first place. Rather they simply look at the mind and body through a somewhat hackneyed technological, reductionist lens which creates more problems than it purports to solve. That is not to say that the Institute is engaged in a dead-born enterprise. Bostrom and his colleagues should be commended for looking to tackle some of the most pressing questions of our time. Notwithstanding, there are a series of underlying presuppositions shared by scholars at the Institute that reflect a disappointingly inflexible ideological platform of their own.

${ }^{6}$ Plato's Meno, for example, can be read as a sustained meditation on the shortcomings of the techne model when it comes to the messy matter of the "science of human affairs". A number of commentators who subscribe to what David Roochnik (1996) dubs the SAT view (standard account of techne) insist that Plato changed tack through the middle and late dialogues and became a theoretical skeptic with respect to morality thereby supplanting the programmatic, optimistic and idealistic moral outlook of the early dialogues. Other commentators, including Roochnik, argue that Plato maintained a consistently skeptical stance concerning the suitability of the techne model for questions pertaining to the good life from the very beginning. This of course is to advance what some might call a continental interpretation of Plato. But, in a sense, such characterizations are unavoidable since the way we read Plato, in itself, reflects the fault line that has seemingly sundered our tradition in the shape of an interpretive series of choices we make when reading even the great inaugurators of that tradition. In other words, a version of our analytic - continental stand-off is evident in our attempts to divine the meaning or implications of Plato's dialogues. That is not to suggest that Plato, for example, should be read as a continental philosopher. That kind of anachronistic approach to Plato or Aristotle is nonsensical but it is one imposed on us by the intransigence of analytic Plato scholars. What a number of recent Plato scholars have tried to show is that much of Plato's work can fruitfully be read as presaging some important, putatively continental approaches to philosophical questions. 
indeed the account of authenticity in one of his first major philosophical publications, Being and Time, can justifiably be described as such. We need an alternative launching pad for the notion of personhood to the technical/reductionist model which typically leaves us with a hopeless and grotesquely vivisected scrapheap where once there was, albeit vaguely outlined, a more holistic sense of personhood. Admittedly, Heidegger repeatedly insists that nowhere does he offer an ethics (and he is keen to remind us that neither does he offer a philosophical anthropology, even as early as Being and Time). ${ }^{7}$ We might say that this is due to his belief that a term like "ethics", generally speaking, already carries a metaphysical legacy which he is trying to overcome. But that is not to say that in outlining Heidegger's account of what it is to be an authentic being, interacting with other beings as similarly authentic in the truth of their own being, we cannot begin to trace the basis for an alternative conception of personhood, albeit one which Heidegger himself refuses to sketch.

\section{PROBLEMS WITH THE ANATOMICAL APPROACH TO PERSONHOOD}

Personhood, like other notions that are close to us, is taken so much for granted as to seem invisible; the familiarity of such concepts breeds a collective indifference or insensibility. ${ }^{8}$ And yet, when it comes to properly examining the question of personhood, as Jane English argues, we struggle to come up with an exhaustive list of necessary and sufficient conditions. The mere fact of being human will not suffice since many people justify abortion to a point on the grounds that the fetus is not yet a person and yet they would hardly deny that the same fetuses are human. For those familiar with the debates surrounding the question of animal rights and the concomitant charge of speciesism, this is also straightforwardly problematic. Given the diversity of individuals that constitute the set of humanity, if all that was required to be a person was to be human, then all kinds of animals that we would typically avoid calling persons would be precluded from being called as much for the simple and rather arbitrary reason that they do not happen to belong to our species; there would be no further morally significant distinction in terms of intellectual ability or emotional intelligence, the ability to suffer and so on. This, of course, entangles us in the question of speciesism and without moving down that road, one can already anticipate the enormous difficulties we might face here. ${ }^{9}$ Pain and suffering on their

\footnotetext{
${ }^{7}$ Heidegger could not be clearer on this issue in Contributions to Philosophy (From Enowning). In the "Preview" he repeatedly dispels what he variously refers to as moral-anthropological and existentiellanthropological misreadings of Being and Time and bemoans the fact that the "temptation is still close at hand to take the entire deliberation in the first half of Being and Time as confined to the range of an anthropology, only with an other orientation." (Heidegger 1999, 48) There are other comments concerning his efforts to steer clear of ethics in "Letter on Humanism". (Heidegger 1998, 268).

${ }^{8}$ Indeed we could line this posture up with what has been called the "false conceit of knowledge" of the interlocutors that Socrates faces in a number of the dialogues. (See Benson 1990)

${ }^{9}$ This raises the question, for instance, as to whether the enhancements that the posthumanist advocates with respect to humans should be made available to animals. That is, suppose we have a scenario whereby a medical breakthrough is made such that we can enhance the brains of human individuals that would otherwise be left severely mentally handicapped. Presumably, many of us would be willing
} 
own will not prove definitive either since too many non-human creatures share this capacity as well. Eventually we are forced to concede that the notion of personhood is a somewhat elusive concept.

Be that as it may, part of the reason that personhood appears to be a "cluster concept" that resists attempts to define it relates to the technical, reductionist approach itself. The anatomizing of personhood does a certain amount of violence to the structural integrity of the whole. We cannot be broken down so easily into parts, nor can we be simply reassembled from those discrete elements; but that does not mean that we are non-coherent amalgams of disparate elements. It is not just the posthumanist who looks to dissect our personhood in this way of course - they rely on a technical interpretive approach that is already entrenched. However, in advocating specific enhancements of discrete components, divorced from any holistic context, they are essentially prescribing treatment and improvements for severed limbs rather than intact bodies. The presuppositions that undergird the analytic approach to this kind of question then are in fact the major source of their own theoretical confusion.

The attempts to define personhood (as is seen repeatedly in debates concerning abortion or the treatment of animals) tend to founder on the issue of limit cases. In other words, various creatures that fit the bill as/answer to the description "human beings" often fail to meet all of the criteria that supposedly constitute personhood. In a way, we are dealing with the kind of problem faced by anyone pushed to provide Socratic definitions for non-analytic subjects. For example, when it comes to what a tree is or what the definition of a tree is, we will find that no list of criteria will ever prove definitive. However, we seem to remain, for the most part, epistemically and practically unfazed by this shortcoming. ${ }^{10}$ There is little or no moral significance, for

to concede that there is nothing morally dubious in intervening in such cases and enhancing these same individuals. The posthumanist might go further and suggest that there is no morally significant difference between that kind of intervention and those that they are discussing regarding the cognitive enhancement of humans with what we might currently deem median cognitive capacities. We are faced however with a possible question concerning speciesism in a different setting. If scientific research could potentially lead to the cognitive transformation of dogs, for example, into creatures that would be as sophisticated cognitively as a human being with what is currently an average IQ; would we see fit to enhance any dog we could in the same way we would the handicapped humans and, if not, why? I suspect that this is the kind of dilemma that the future humanist would be willing to concede but would rather avoid. Notwithstanding, I don't see it as an argument against posthumanism per se.

${ }^{10}$ Though, this same difficulty with respect to trees reveals again how the search for technical definitions is not always the best strategy; and yet we cannot simply decide that trees can no longer be spoken of. Socrates repeatedly exhorts his interlocutors to offer technical, analytic definitions of ethical terms in Plato's dialogues, but one wonders what his interlocutors might have said if they were discussing whether or not a forest of trees was aesthetically pleasing and Socrates refused to be drawn on the subject before they had offered a comprehensive and exhaustive definition of the word "tree". As it happens, this issue has led to legal headaches from time to time since finding an overarching definition of a tree proves next to impossible. I recently discovered a newspaper article which reported on a case where a presiding judge had taken twelve thousand words to "define a tree". Justice Cranston was interested in the legal definition of a tree in terms of tree preservation orders and ruled in the case in question that a sapling clearly counted as a tree and that a previous ruling which determined that a tree's trunk had to reach a certain minimum diameter in order to count as a tree was erroneous: "with 
example, riding on the question as to what constitutes a tree. And, if Socrates himself were to push us for the definition of a tree, we might concede eventually that we cannot offer a definition of a tree in the same way that we might be able to furnish a definition of something in geometry which deals with self-evidence or analytic truths. All of Socrates' vexations concerning the definition of a tree would not stop us from saying whether a tree in our garden is green or tall or deciduous and so on. We would continue to speak of trees rather than passing over them in silence even though we could not offer the definition of a tree which Socrates would wish to identify before proceeding. The same is not true when it comes to the question of personhood, which has been the subject of some of the more hotly contested debates in contemporary moral philosophy. We have continually struggled and failed to provide exact and exhaustive definitions of personhood and we don't seem content to accept the notion of personhood as loosely defined or non-technical. And, to make matters worse, the posthumanist, incognisant of this difficulty it would seem, routinely proceeds with a half-baked, pseudo-technical understanding of personhood as though it were indubitable.

Granted, we typically don't need to distinguish between terms like "human being" and "person" in order to make sense of experience. We are not normally crippled with perplexity when someone uses these terms; indeed, most of us would tend to treat the

tree preservation orders there are no limitations in terms of size for what is to be treated as a tree. In other words, saplings are trees". (Adams) From there I began to scan through various textbooks and studies of trees, as I could lay my hands on them, only to find that, for the most part, the subject of these various studies - the tree/trees, remained undefined or rather loosely defined. Eventually, I found the following insightful and, dare I say it, philosophically penetrating entry in Colliers Encyclopedia, Vol 22:

TREE, a perennial woody plant that typically [not necessarily] has a single upright stem, or trunk. A more precise definition is difficult to formulate because of the range of sizes and the diversity of habits of plants considered by various people to be trees. For example, banana plants often are referred to as trees, but they are herbaceous rather than woody. Many previous definitions have included the condition that the trunk of a tree divides into successively more numerous and smaller segments, called branches and twigs, which bear leaves, or that trees have distinct crowns of foliage. A palm tree, however, has an unbranched trunk topped by a cluster of large leaves; and the woody trunk of the giant tree cactus, or saguaro, may have one or a few thick branches but is leafless.

Most definitions include a statement on height, but the minimum height to qualify as a tree ranges from 8 to 20 feet in the view of different authors. Some definitions pertain to individual plants, but others pertain to species. Thus, a low plant at timberline on a high mountain or in the Arctic may be considered a tree because it belongs to a species whose individuals usually grow to large size. In a favorable site the plant has the inherent capacity to grow to large size, but adverse environmental conditions at timberline limit its height to a few feet. Other plants ranging from a few inches to several feet tall, particularly many forms propagated by nurserymen, and bonsai dwarfs, are considered trees because they have single trunks and conspicuous crowns. A large plant that would be recognized as a tree by any of the many definitions began growth as a seedling and gradually grew to large size. Was it a tree from the time it germinated, or from the time it reached a height of 8,10, 12, 15, or 20 feet? While these are legitimate questions, they have no scientific answers. Although rigid definitions may be required for certain undertakings, 'tree' is a concept that always will be interpreted more liberally by some people than by others. (McCormick 1972, 448; my emphases). 
terms more or less synonymously. But when faced with the moral dilemmas alluded to above, we have persistently looked to determine the meaning of "personhood" in the same way that Socrates' interlocutors try to satisfy the latter's demands for technical definitions. The reason we have found ourselves dissatisfied with the biological definition of a human being as sufficient for personhood, for instance, relates to the fact that that definition is of little use when it comes to the moral positions that look to stake their claims with varying standards or accounts of personhood. ${ }^{11}$ We find that we can offer a suitably adequate definition of the term "human being"12 then, but we will begin to struggle when it comes to the term "person". Most likely, we would begin with the assumption that a person is a human being. But, without moving too far in any particular direction, we already know that the mere fact of being human will often not do enough work for an account of personhood, enough work, that is, such as to resolve all of the difficulties that emerge in moral debates. To put things rather simply, any attempt to define personhood typically moves in one of two directions: commentators either try to lower things down to such widely held common denominators of human experience that the classification personhood cannot justifiably be thought to not apply to all kinds of non-human animals, or else, in the attempt to avoid this result by establishing the exclusively human character of personhood, commentators propose criteria which would ultimately preclude all kinds of human beings whose personhood we are loath to relinquish. There are many human beings that, for one reason or another, do not have the capacity to function, for example, as moral agents and yet we would still classify them as "persons". For example, a severely retarded human being, or a very young infant would not qualify as a moral agent and yet we still count them as persons. So, while many people are moral agents, there are lots of people who are not, thus moral agency is certainly not the criterion required.

Jane English demonstrates effectively how attempts to come up with an exhaustive list of necessary and sufficient conditions regarding the notion of personhood are bound to fail and characterizes the notion of personhood as a "cluster concept", which is a useful enough image. English stops short of suggesting, however, that the attempt to find a technical/theoretical definition is a major source of the relevant difficulties to begin with. In other words, she seems to simply accept that we begin with a concept (personhood), of which we have a vague, average understanding before then attempting to offer a more technical, comprehensive, scientifically adequate account when pushed. In demonstrating how these efforts typically unravel, however, we also need to address the question as to where the vague, average understanding of personhood comes from, and whether or not there are other ways of thinking about the concept that do not require us to simply render it a murky puddle of notions, or a cluster concept without any cohesive agent. In other words, what if it is the technical approach itself that renders the notion of personhood

\footnotetext{
${ }^{11}$ For a discussion of this issue, among others, in the context of a critical overview of the notion of personhood in moral philosophy see S. F. Sapontzis 1981.

${ }^{12}$ Presumably we will offer some generic account of what the term 'homo sapiens' involves.
} 
as such? What if this is the wrong type of approach? What if we do not simply accept the Socratic challenge at the outset? Is that perhaps what Plato was trying to suggest in some of his dialogues? That is, that sometimes the technical approach (i.e. the conviction that we must begin with a technical definition) simply won't work when it comes to certain types of questions. Then how might we begin?

\section{A NON-ANATOMICAL ACCOUNT OF PERSONHOOD}

We seem to have some basic sense of what being a person means, it is perhaps imprecise, it maybe begins to creak if we try to establish moral principles of inclusion and exclusion upon it which typically involves trying to beef up the technical side of the definition. But before trying to supplement the definition in that fashion, what if we examine where our immediate, non-technical, average sense of personhood comes from? Clearly being biologically human, in and of itself, doesn't seem to necessarily play a major conceptual role at the pre-reflective stage; we are not interested in the biological backdrop to personhood in this context. We are usually thinking more in terms of a site of experiences, in short, our emotional experience. Take, for example, the frequency with which we personify all kinds of non-human creatures. Even in our fantastical conjectures regarding extra-terrestrials in science fiction we tend to personify them in some way. When we personify an alien, for example, for the most part, we tend to focus on their affective capacities, that is, we usually take it as a given that they are cognitively advanced, but we are interested in whether or not they would have an affectivity that would allow for empathy or mutual identification. The kinds of questions we seem inexorably drawn to involve how they feel about things. In other words, will they respond affectively to situations as we do? Our tendency is to speculate about them as emotional beings. A similar trend is noticed in other popular science fiction genres, for example, cinematic treatments of artificial intelligence. In movies that tackle the question of Artificial Intelligence, the overriding concern of the narratives typically relates to the issue of emotional experience. Much of what we might once have been impressed by in terms of computation and physical strength can be understood readily enough in terms of computers and machines with painted faces. What ultimately fascinates us is the idea that something that is not human could have something comparable to our emotional experience and thereby the ability to experience the world in all of its affective depth the way we do. The focus is nearly always on the personhood of these non-human entities which is both measured and attested to by their capacity for emotional response. Ultimately, fascination with superhuman mental or physical prowess is a response to novelty and is rarely the focus of these stories; the meat of these stories involves emotional relationships and how we in turn come to identify machines as people and no longer as mere machines. Again and again writers, film-makers and story tellers return to this theme of human emotions as being central to any account of humaneness and empathy, in short, the ability to treat others as persons deserving of respect in their own right. The specifics of their genetic or biological or material composition are deemed irrelevant to the question of personhood, the issue of 
personhood relates exclusively to the idea of an awareness that appreciates and feels what we ordinarily call human emotions. Of course, from a Heideggerian standpoint, there is a fundamental misapprehension on the part of those who speculate in these ways concerning affectivity in that the temporality or possibly non-temporal nature of these creatures is largely ignored, where, for Heidegger, this is central to any account of our affective understanding, self-identification and projection. As such, the supposition that commensurate emotional awareness would develop in suitably intelligent non-human machines, for example, misses the historical constitution of human interpretation, understanding, in short, how time conditions the way we feel. Leaving this important criticism to one side, for the moment, we simply wish to establish that affectivity, however it is understood, is central to any account or understanding of personhood. The question as to how time or temporality should be brought to bear on any account of affectivity is something we will treat of shortly.

Consider our fascination with the biographies of famous people. More often than not, what intrigues us most is the possibility of a glimpse inside their mind, and this usually means that we are interested in them as emotional beings. When reading accounts of Beethoven's life, for example, we wonder what kind of person he was? What must it have been like to be Beethoven? How did Beethoven experience a world which, in certain respects, we share? One might object that this is not necessarily the case when one reads about Hitler, for example, and yet, in attempting to render Hitler as a creature we cannot empathize with, a non-person, if you like, who lacks the personhood that normal people identify with, we are simultaneously acknowledging the primacy of the affective in how we relate to and interpret the world and other people. It is through the affective that we relate, that we interpret. This goes some way toward explaining, perhaps, the recurring tendency to depict figures like Hitler as diabolical creatures that lack any vestige of personhood. We sidestep many of the discomfiting issues involved by simply suppressing or denying the personhood of such figures.

So, what can we discern here? Well, in short, the central role occupied by the emotions - the affective. It is at an emotional register that we have our most immediate sense of something like personhood and perhaps that should also be our clue when it comes to figuring out how we should proceed. If we begin to think of ourselves, or of persons, as the beings that feel in various ways, then we might begin to see a way forward. As with the attempts of Platonic characters responding to the Socratic challenge, the attempts to use the technical model are frustrated when we look for axiomatic definitions of personhood. The analytical incisions of the technical approach will not uncover the hidden glue of personhood after dissecting its 'pieces' anymore than the surgeon's scalpel will fix a plethora of psychological problems that ail us. To dis-integrate something is not necessarily to understand how it is integrated, particularly if it is not a machine of our own design or construction and indeed is not well captured by the machine analogy to begin with. ${ }^{13}$ One can already anticipate a

\footnotetext{
${ }^{13}$ As Schechtman writes, when discussing the shortcomings of psychological-continuity theory: "The pieces that make up a person's psychology, must, to fulfil this purpose, be viewed to be as discrete and
} 
move that is available here whereby the posthumanist concedes this and says, "okay, what if we only deal for now with conditions that are either necessary or sufficient or both and determine whether or not we can improve them in ways that are uncontroversial?" And of course one can quickly turn a slippery slope around and suggest that from there it is an easy, well-lubricated slide toward the more fantastical interventions advocated by many posthumanists. But this is merely an example of what we shall discuss below regarding Heidegger's worries over our commitment, if not enslavement, to a technological filtering lens through which we view, or perhaps, process the world. Looked at in a technical way, if we take any one of the necessary or sufficient conditions of personhood on their own, we cannot identify any particular one of them as definitive or constitutive of personhood and no particular assembly or arrangement of a list of conditions taken collectively would be either exhaustive or definitive either. That is, any particular feature of personhood which the posthumanist would look to enhance or improve would be either a necessary or sufficient condition of personhood as part of an account that actually lacks a definition of personhood. This lack, moreover, is a result of the reductive, technical approach to a subject that requires a rather different one that takes note of the pre-reflective, affective backdrop to our ordinary, everyday sense of personhood.

\section{HEIDEGGER, HISTORY AND PERSONHOOD}

The question of history was one that Heidegger had already identified as crucial before his earliest encounters with Husserl or his confrontation with Kant's critical philosophy. In letters to his then fiancé, Elfride, Heidegger (still only in his mid-20s) was already quite critical of two of the most important influences on his early philosophical vision for what he took to be a fatal shortcoming: their entire neglect of the question of history. Of course, Heidegger does not mean something so simple as knowing the events that make up one's own external life in chronological order, much less significant facts and dates in school books. Rather Heidegger means a more primordial notion of history for a creature that lives in the liminally projected certainty of its temporal limits at any given moment. In 1915 the young philosopher was already critical of certain aspects of Kant's critical philosophy as evidenced in a letter to Elfride:

Today I know that there can be a philosophy of vibrant life [des lebendigen Lebens] that I can declare war on rationalism right through to the bitter end - without falling victim to the anathema of unscientific thought - I can - I must - \& so I'm today faced by the necessity of the problem: how is philosophy to be produced as living truth \& as creation of the personality valuably and powerfully.

detachable as are the planks of a ship or the grains of sand in a heap. It is because psychologicalcontinuity theorists are trying to force the insights gained from consideration of questions of selfknowledge and responsibility into the mold of questions of the persistence of material objects that they are forced to view psychological states as atomic, isolable, and in principle independent of the subject who experiences them - a view that I have argued to be highly implausible." (Schechtman 1990, 89) 
The Kantian question is not only wrongly put - it fails to capture the problem; this is much richer and deeper.

We must not give our heroes stones instead of bread when they come back hungry from the battlefield, not unreal and dead categories, not shadowy forms and bloodless compartments in which to keep a life ground down by rationalism neat and tidy and let it moulder away. (Heidegger, 2008: 17)

A couple of years later, revealing his earliest impressions of Husserl, Heidegger has the following to say to Elfride in a letter dated Whit Sunday, 1917:

I cannot accept Husserl's phen[omenology]. as a final position even if it joins up with philos. - because in its approach \& accordingly in its goal it is too narrow \& bloodless \& because such an approach cannot be made absolute. Life is too rich $\&$ and too great thus for relativities that seek to come close to its meaning (that of the absolute) in the form of philos. systems, it's a question of discovering the liberating path in an absolute articulation of relativity.... Since I've been lecturing, up to now I've constantly experienced these sudden reversals - until 'historical man' came to me in a flash this winter. (Heidegger 2008, 33)

In both of these passages Heidegger emphasizes the lack (in Kant and Husserl) of what he was to see as central to his own project: the historical situatedness of the human being. Our history, in Heidegger's sense, is constitutive of the way we perceive and interpret and allows us a multi-dimensional vision of life as opposed to the overly contrived, lifeless nature of other accounts. And, we might say, it should form part of any conception of what an authentic person is like and what their life involves.

For Heidegger, what is constitutive, at bottom, of the way we experience existence is the fact that things matter to us; that we have aims and desires infused with varying levels of affective urgency. At the heart of the dynamic structure of our existence are affective moorings which are conditioned by the ultimate existential anchor, time or temporality. The fact that being for us is set against the backdrop of the possibility of not-being, that is, of a previous having been and not having been and a future to both be in and eventually not be in, is the ultimate determining condition behind our entire interpretive apparatus. We are facing an important question in this regard with respect to the ultimately tragic nature of existence and how much of what we currently hold dear and value as rudiments of existence are conditioned by our appreciation of a tragic fate which we dread. ${ }^{14}$ There are a whole

\footnotetext{
${ }^{14}$ I am thinking here of Heidegger's treatment of the tragic, inexorable nature of our situation in Introduction to Metaphysics. Take for example passages such as the following: "There is only one thing against which all violence-doing directly shatters. That is death. It is an end beyond all completion, a limit beyond all limits. Here there is no breaking forth and breaking up, no capturing and subjugating. But this un-canny thing, which sets us simply and suddenly out from everything homely once and for all, is not a special event that must also be mentioned among others, because it, too, ultimately does occur. The human being has no way out in the face of death, not only when it is time to die, but constantly and essentially. Insofar as humans are, they stand in the no-exit of death. Thus
} 
range of emotions that we cherish as colourful threads in the tapestry that is our identity which are conditioned by the limits of our existence. They do not seem to be demoted or diminished by medical advances that allow people to live longer now than they did, for example, in Shakespeare's time. When we read Shakespeare's Sonnet No. 60, which opens with the lines "Like as the waves make towards the pebbled shore/So do our minutes hasten to their end;" we are moved by the familiarity of sentiments that echo our own rueful reflections on the transient nature of life. ${ }^{15}$ Granted, when faced with the imminent loss of life, or indeed our projection of a future where we will quite possibly face our demise knowingly, the fact that that same feature of our historical identity (namely its temporal limits) is part of what makes life as special or significant as it is comes as rather meagre comfort. When we reflect on the fact that we are all essentially on death row, we tend to be less prone to cavalier, devil-may-care attitudes toward our continued existence. The very notion can be deeply, deeply disconcerting. The prospect of being reprieved from so grim a fate as the erasure of one's own ego or identity can be enormously appealing ${ }^{16}$; but we have to be clear on what life would mean for such a creature, not least since such a creature would not be one of us. We are left with the question then: if history is a part of our dynamic existential identity, then is the posthumanist ideal one where

Being-here is the happening of un-canniness itself. (The happening of uncanniness must for us be grounded inceptively as Being-here.)" (Heidegger 2000, 168-169).

${ }^{15}$ The fact that life expectancy has increased significantly beyond what was typical in Shakespearean times then has not altered the fundamentally temporal constitution of our personhood. That is, whether the average life expectancy is 30 or 60 or 90 years does not seem to alter the fact that temporality/finitude plays a central role in our sense of personhood. The issue of continued attempts to improve quality of life and life expectancy then must be distinguished from the fantasy of enhancing the species beyond its temporal limits through technology such that the resulting creatures would no longer be susceptible to death. That is, they would be temporally limitless creatures, and indeed would no longer be human but post or trans human.

${ }^{16}$ The question as to what ramifications the belief in an afterlife might have for Heidegger's account of temporality could be seen as bearing directly on our argument. Heidegger argues that our entire experience of the world and ourselves, as well as our ability to understand, interpret and project is filtered through a temporal lens. The more we examine our projects and the hidden and not so hidden structures of our project-oriented lives, the more we see in all of them the constitutive influence of our temporality. So how do we reconcile this conviction on Heidegger's part (one of his most important and enduring insights for many) with the fact that so many people profess to be theists and supposedly subscribe to the notion that their ego, or spirit or soul, that thinking and feeling part of themselves, doesn't vanish as soon as they have shuffled off this mortal coil? If they have such a non-finite view of themselves, then how can radical finitude be operative in the way that Heidegger proposes? The fact remains, however, that no matter how often we are told of the consolations of faith or religious belief that same, faith-based type of belief does not seem to diminish the fear of death in the great majority of people. One might say that people merely fear the unknown in such cases, but I would suggest that that is a little obtuse. When it comes down to it, our temporal awareness seems unaffected by any beliefs in an afterlife or a life beyond temporality since it is outside the manifold of experience for us. We are rather firmly earthed when it comes to our ability to interpret and understand and whether or not we hold out hope or belief in some kind of existence subsequent to this one, we are epistemically entrenched in the finiteness of this existence - the temporal structure seems ingrained! For an example of the ill-conceived lengths some thinkers have gone to in trying to undermine the priority Heidegger affords finitude as part of our ability to interpret and understand the world, see Frederick Sontag 1967. 
history has no end for us and thus loses its essence insofar as our future becomes an anchorless horizon of endless existence? Is that the aspiration? I do not pose these snidely as rhetorical questions, rather the gravity of such questions and their ramifications for how we understand personhood can scarcely be overstated!

That is not to suggest that very different types of creatures living very different sorts of lives might not have a dignity and worth all their own. But we do have to face the question as to what it is that makes this life worthwhile or meaningful and, I would submit, our historical situatedness and our finitude are ultimately a major part of what constitutes its significance and worth for us. Our existential history is affectively and interpretively constitutive. Some may aspire to a ceaseless euphoric existence at a level of extreme cognitive functionality ${ }^{17}$; but one wonders as to the all too familiar utopian ring to such aspirations. Notwithstanding, even leaving the wellrehearsed criticisms which typically accompany such suspicions aside - it seems to me that we need to get clear on how much of what we currently do take as fundamental to our dignity would be made obsolete by certain enhancements. The quest for the Holy Grail, the magic elixir or gift of immortal life have ever been mainstays of human fantasy, but what kind of effect would such a change actually have? Death, that is, our projected temporal finitude, is one of the interpretive anchors to our existence. It sets our affective field of vision if you like, sets the manifold into limits of sorts. If coming-to-an-end no longer is the converse of coming to be, then what kind of effect would this have? It would certainly involve a radical change in how we experience life; but of course, we cannot say that it would of necessity be bad. The fact that things are this way does not mean that they ought to be this way. Nevertheless, a description of what makes life matter to us in such a scenario is still

\footnotetext{
${ }^{17}$ And yet even moments of intense ecstasy, I would submit, owe part of their allure to their contrast with the less intense quality of our daily life. John Stuart Mill himself is critical of the excessively hedonistic conception of happiness that utilitarianism was sometimes erroneously characterized as aspiring toward. Instead, happiness for him involves a realistic and realizable balance where the high points of ecstatic existence are weaved into a life where one is able to maintain something of an even keel, a predominance of the active over the passive and the good fortune not to have to endure the trials of Priam. Mill is, in this sense, a good old Aristotelian: "If by happiness be meant a continuity of highly pleasurable excitement, it is evident enough that this is impossible. A state of exalted pleasure lasts only moments, or in some cases, and with some intermissions, hours or days, and is the occasional brilliant flash of enjoyment, not its permanent and steady flame. Of this the philosophers who have taught that happiness is the end of life were as fully aware as those who taunt them. The happiness which they meant was not a life of rapture; but moments of such, in an existence made up of few and transitory pains, many and various pleasures, with a decided predominance of the active over the passive, and having as the foundation of the whole, not to expect more from life than it is capable of bestowing. A life thus composed, to those who have been fortunate enough to obtain it, has always appeared worthy of the name happiness. And such an existence is even now the lot of many, during some considerable portion of their lives. The present wretched education and wretched social arrangements, are the only real hindrance to its being attainable by almost all." (Mill 1991, 143-4). Of course, we are always going to struggle to offer strictly delimited boundaries or cut-off points with respect to these kinds of issues. Asking questions like "how much pleasure is too much pleasure?" doesn't really make much sense. However, a cognitive enhancement that would allow us to walk around the world in a state of unrestrained euphoria...does that strike us as desirable? Surely a part of ecstasy involves its rarity and this seems to be something that we collectively cherish.
} 
lacking on the posthumanist's account. Furthermore, any 'values' that might be espoused as life-affirming or worthwhile are all currently supervened on by our thoroughgoing sense of our limited, temporally historical nature; if we were temporally limitless creatures, then the way these values retain their significance would undoubtedly change as well. Our ability to 'be' and our concomitant temporal limits are constitutive of our ability to feel, to value, to both love and hate!

A more realistic immediate possibility, of course, is that we will begin to see the continued extension of human life expectancy. We can expect that centenarians will no longer be so few and far between with multiple generations within the same families managing to co-exist. But we must preserve our ability to distinguish between the various attempts to improve the basic quality and longevity of our lives from the desire to improve and enhance beyond any sense of what it is to be a person in the first place, in other words, creatures who have little or no concept of ending or dying since it is a massively diminished possibility for them. ${ }^{18}$ Again, that is not to say that a radically mortal life is a superior one, but it is central to any conception of personhood and existential significance. One might wonder as to whether the entirely natural desire to increase one's well-being and life-expectancy could lead to a situation where we move beyond humanity to 'posthumanity'? At what point are we moving away from life-extension to something which is beyond that human aspiration? The posthumanist suggests of course that we are dealing with differences of degree or that we are trying to put a road block on a slippery slope. In other words, there is ultimately no difference in kind between offering someone the latest medical treatments and in fact the desire for immortality. To want not to die prematurely then is seen as consistent with wanting to live a life with no temporal horizon. Admittedly, this is a difficult place to draw a line in the sand, as it were, since the sands of human life-expectancy are constantly shifting. Notwithstanding, part of a person's self identity is anchored in a sense of their finitude and the fact that they fear their own earthly demise does not eliminate or undermine that aspect of their conception of themselves as people. While many of us may well want to live past tomorrow or next year, it is not ultimately clear that any of us would genuinely want to live forever.

\section{SUBJECTIVITY AND PERSONHOOD}

So what role does subjectivity play in all of this - in a person's conception of themselves or their identity? The dominance delusion or, if you like, the illusion of autonomy under which we typically labour seems to dupe us into the belief that our lives and existence are completely within our control. First of all, given our temporal moorings, as discussed above, we can see that that is ultimately not the case. Heidegger vitiates this operative assumption in Western philosophy (and no doubt this is his great attraction for students of Eastern thought), which was cemented in

\footnotetext{
18 "If we learn to control the biochemical processes of human senescence, healthy lifespan could be radically prolonged. A person with the age-specific mortality of a 20 -year-old would have a life expectancy of about a thousand years." (Bostrom 2007, 16)
} 
early modern stone, according to Heidegger, with the Cartesian cogito, where everything is seen ultimately as a condition of our own cognition and action. Heidegger calls instead for releasement to things (Gelassenheit). He is not so much calling for a diminishment of responsibility or a subjugation of one's will - rather he is criticizing erroneous conceptions of autonomy and selfhood. We cannot ignore our historical, cultural and social embeddedness. And in acknowledging these facets of our daily lives, we are relinquishing our hold on a phony subjectivity with pretensions to absolute self-sovereignty in a world where technology is interpreted as a mere means to further our ends. One can, however, learn to live in harmony with our world and to find our authentic rhythm within it. We can first manage this by getting clear on what it means to be one of $u s$; we begin by acknowledging our true potential as temporal creatures, thrown into historical and cultural traditions with an open but limited future lived out amongst those who are like us and who are similarly determined in advance. We have possibilities available to us, but they are limited by our capacities, the environment we are in, the mores and laws we are governed by and the fact that we have limited opportunities in a limited amount of time within which to get anything done; if we had eternity then the sense of urgency would diminish from our various projects. And this in turn, paves the way for a richer sense of what it is to be another also.

Heidegger is often excoriated by commentators for his failure to provide an account of the other as part of his account of authenticity. (See Gadamer 2003, 22-3 and Carman, 2003, 268-71.) It could be argued however that treating others as we treat ourselves, from the standpoint of authenticity, would involve seeing the truth of our own situation and realizing that others are in the same situation. As Nietzsche wrote in a letter to Franz Overbeck: "what is this our life? A boat that swims in the sea, and one knows for certain about it that one day it will capsize." (Nietzsche 1881) And we might say then that the ultimate ground for sympathy emerges from a realization that we are all in the same boat, so to speak. Or, if we are to be strictly Heideggerian, we are all in our own boats, but in the same sea awaiting a similar fate. That is, we share structurally identical existential situations, and, thus, we recognize the similar situation of others, their existential potential and treat them accordingly, as we in turn hope to be treated ourselves in order to constitute a community of authentic intersubjectivity. Heidegger's adumbrated discussion of the notion of "leaping-in for" as opposed to "leaping-ahead for" clearly has something like this in mind! In Being and Time, Heidegger describes what he sees as the conditions for the possibility of inter-subjectivity. Genuine inter-subjectivity involves not leaping-in for but leaping-ahead for another person. (Heidegger 1962, 158, 159) In other words, to leap-in for is to close off the potentiality or possibilities for another person by assuming control of their future in some immediate sense or other and determining a course of action on their behalf. This can happen in all kinds of immediate, quotidian ways. The example sometimes used is of someone trying to help a child solve a mathematical puzzle or problem. There are two approaches that might be adopted; one person might simply ignore the child's latent capacity to figure the problem out. Another person might try and nurture their fledgling analytical capacity to wrestle 
with the problem and through a series of progressive steps begin to allow them to realize their intellectual potential such that they can solve these problems by themselves. This kind of approach would be more in line with leaping-ahead for the child, appreciating their potential and allowing it to blossom and develop. The lazier approach is to suppress their potential and to leap-in for the child removing their authentic future in this sense by simply telling them the answers or showing them how to get the right answer without having to fulfill their own critical/analytical potential. This would be the inauthentic correlate of authentic inter-subjectivity. These varying approaches to other people correspond with either a more general leaping-in for another or a leaping-ahead for another, that is, taking someone else as a temporal creature with an horizon of possibility and an historical situation in their own right or else simply taking them as some kind of creature that is present and denying their future in that sense, that is, taking them as simply relevant to some objective or other; they are looked at, in that case, in purely functional terms as someone that can facilitate some project or other. The condition for the possibility of sympathy then would be to acknowledge the temporality of another person, the beingtoward-death of another person, in short, their authentic potentiality for being.

\section{TECHNOLOGY AND ENFRAMING}

Finally, but no less important for all that, we have to wonder as to our unquestioning confidence in technology (especially computer technology) and the way it has shaped our understanding of personal identity and the mind. Why is it that our minds and identities are almost exclusively described in the techno-speak of, for example, information processing? Bostrom himself uses the term technocentric to describe this tendency; remarkably, Bostrom uses the word positively and sees it as an unproblematic feature of his approach: "Given the technocentric perspective adopted here, and in light of our incomplete but substantial knowledge of human history and its place in the universe, how might we structure our expectations of things to come?" (Bostrom 2007, 9) First, of all, as Bostrom confirms, the perspective of he and his colleagues is technocentric and it is a technocentrism which they endorse unquestioningly but one which we characterize as problematic in its own right and, in fact, as being highly symptomatic of Enframing. Moreover, he invokes, in this context, the important role to be played by human history and yet proceeds again with the fundamental role occupied by temporality and historicity in terms of human history left unaddressed. It is as if history is to mean nothing more than a static chronicle, a repository of past events which we can access with a view to acquiring useful information instead of seeing its active, dynamic role in shaping our self understanding.

Perhaps one of the most disconcerting examples of this technical prejudice/ technocentrism is to be found in the following description of "uploading" which, to my mind, is so self-evidently problematic that it scarcely necessitates further comment: 
Uploading refers to the use of technology to transfer a human mind to a computer. This would involve the following steps: First, create a sufficiently detailed scan of a particular human brain, perhaps by feeding vitrified brain tissue into an array of powerful microscopes for automatic slicing and scanning. Second, from this scanning data, use automatic image processing to reconstruct the 3-dimensional neuronal network that implemented cognition in the original brain, and combine this map with neurocomputational models of the different types of neurons contained in the network. Third, emulate the whole computational structure on a powerful supercomputer (or cluster). If successful, the procedure would [sic] a qualitative reproduction of the original mind, with memory and personality intact, onto a computer where it would now exist as software. This mind could either inhabit a robotic body or live in virtual reality. In determining the prerequisites for uploading, a tradeoff exists between the power of the scanning and simulation technology on the one hand, and the degree of neuroscience insight on the other. (Bostrom 2007, 22)

Bostrom defends this kind of technical reductionism throughout his work arguing elsewhere, for example, that

Cognitive enhancement is based on the unity between the biological brain and the mind, and the unity between different kinds of information processing. Changing biological processes enables changes to the mind (and vice versa). Information processing is the same whether a brain or a computer does it. It hence lends itself well to the vision of converging technology. (Anders Sandberg and Nick Bostrom, 2006, 215)

\section{N. Katherine Hayles responds to such proposals in How We Became Posthuman:}

I was reading Hans Moravec's Mind Children: The Future of Robot and Human Intelligence, enjoying the ingenious variety of his robots, when I happened upon the passage where he argues that it will soon be possible to download human consciousness into a computer. To illustrate, he invents a fantasy scenario in which a robot surgeon purees the human brain in a kind of cranial liposuction, reading the information into a computer. At the end of the operation, the cranial cavity is empty, and the patient, now inhabiting the metallic body of the computer, wakens to find his consciousness exactly the same as it was before. [H]ow, I asked myself, was it possible for someone of Moravec's obvious intelligence to believe that mind could be separated from body? Even assuming such a separation was possible, how could anyone think that consciousness in an entirely different medium would remain unchanged, as if it had no connection with embodiment? Shocked into awareness, I began to notice he was far from alone. (Hayles 1999, 1)

Neil Badmington, who discusses this passage in "Theorizing Posthumanism", notes the irony here: "the seemingly posthumanist desire to download consciousness into a gleaming digital environment is itself downloaded from the distinctly humanist matrix of Cartesian dualism." (Badmington 2003, 11) Of course the concerns of both of these critics are well taken and the issue of embodiment in particular is a crucial one. However, there are other problems which surface again here that relate to the central arguments of this paper. Yet again, there is the problem of the absolute 
temporal invisibility involved; under this type of technocentric reductionism, no allowance is made for the affective and thereby temporal backdrop to human consciousness. Furthermore, this kind of technocentrism is a symptom of a corrupted type of interpretation, not a neutral or indeed necessary way of understanding ourselves and others. Reducing the human mind to the processes of a computer is a highly problematic, tendentious and presupposition-laden move.

Why have we allowed this technocentric language to hold sway in such a monopolizing, eliminativist fashion? The less than obvious problem, then, as a result of its universality, pervasiveness and thus familiarity is technology and the role technology plays in our lives. The posthumanist may well argue that this is a phoney problem. If someone has a problem with their heart, we do everything in our power to fix it - what is so different then about enhancing someone's brain such that they are capable of thinking at the level of an Einstein or Newton? No doubt people from a couple of centuries ago would be astounded at the positively Frankensteinian notion that today we can replace one person's heart, for instance, with someone else's. As Nick Bostrom points out, someone from a previous historical epoch might well be astounded at our current life-expectancy, among other things: "life-expectancy is three times longer than in the Pleistocene....In the eyes of a hunter-gatherer, we might already appear 'posthuman'." (Bostrom 2005, 213). Our own resistance then to the proposed improvements of the posthumanist, according to Bostrom, are the mere prejudices of a certain intellectual provincialism or traditionalism! Aside from the unforgivably speculative nature of that kind of criticism through an unwarranted (and thereby false) analogy ${ }^{19}$, there is the question as to whether or not there is something a little different involved which should give us pause. Part of the difficulty here relates to what Heidegger, I believe, would see as the loss of an ability to identify differences, to make distinctions, to avoid a monochromatic view of ourselves and the world we inhabit. Depending on one's interpretive filtering lens, the differences between certain events, objects or actions can seem relatively inconsequential. For example, if we were to describe the activity of plunging a knife into a mattress with, say, the carcass of a pig, and if we are to describe things on a purely molecular level, the differences might appear to be simply matters of degree and not kind. However, if the pig is alive, we might find ourselves baulking at the idea that the only language which is relevant here is the one that describes things on a molecular level. The difference involved when one brings suffering into the equation, and perhaps loss of life, seems inadequately treated under the rubric of molecular change. We don't necessarily have to make the further leap to human beings for the difference to appear to be one of kind and not degree which demands that we speak with a language which does not restrict us to mere changes of degree in this example. The language is

\footnotetext{
${ }^{19}$ It is merely presumed that the changes being postulated will be accepted as commonplace by future generations. There are two problems with this. First, the mere possibility that future generations would be unfazed by something that we might find problematic does not in itself mean that there is nothing problematic. We might call that a "will/ought" argument. Secondly, there is no guarantee that the changes being spoken of would ever be deemed acceptable by a future society. Thus there are two unwarranted presumptions buttressing this particular objection/rejoinder.
} 
inadequate to the scenario; restricting us rigidly to this language then would be wrongheaded - the strategy of an eliminativist ${ }^{20}$ in this type of situation is erroneous. Who is to say that a language which seems counter-intuitive at best when we're looking for the most comprehensive description of the killing of a live animal with a knife compared to the plunging of the same knife into an inanimate object is the only acceptable one? It would seem hamstrung by an explanatory poverty of its own. In a way, we're back to the Platonic problem we invoked at the outset - the wrongheaded attempt to use the technical/theoretical model of the exact sciences to make intellectual progress in inquiries where the language of that model simply doesn't work! One approach, one Plato in fact anticipated, ${ }^{21}$ is to insist that these issues then cannot be spoken of rather than seeing that different kinds of language are needed for different kinds of subjects. ${ }^{22}$ For example, a mathematical account of music may well be interesting, enlightening or illuminating; but it hardly exhausts the topic. The eliminativist approach suggests that other languages and descriptions are really just superfluous or arcane and anything which cannot be expressed in their own predetermined, technical terms is really just nonsensical. Indeed, on some issues, I am sympathetic to that view and the concomitant critiques of certain examples of folkpsychology for example. The problems begin with the extension of that eliminativist conviction to every issue faced by humans when, in fact, they cannot all reduce to the same technical discourse; that fact alone does not make them superfluous or nonsensical. After all, how many of us would be willing to concede that someone analyzing data in a sound laboratory and recording the frequency of sound waves with computer equipment understands Beethoven's Ninth Symphony better than the composer himself? There is something deeply, intuitively implausible about that idea! Beethoven may not have had any proficiency with the technical language of the

\footnotetext{
${ }^{20}$ I use the term "eliminativist" in the context of this paper to refer to the kind of reductionist attitude so prevalent today. I am not thinking solely of the eliminative materialist, but rather of the extension of that attitude to many facets of human existence whereby the technical narrative is taken, more or less unquestioningly, as the only legitimate one.

${ }^{21}$ I take this to be, in part, the implication behind Meno's articulation of an apparent paradox in the middle of the eponymous dialogue. Socrates' resolution of the paradox and the more general strategy of the dialogue demonstrate the necessity of the nature of inference with respect to mathematical problems when it is in fact the question of virtue and where and how one begins to make inferences with respect to virtue (which they fail to even define) which is at issue. Meno had initially concluded that one cannot speak of virtue at all when all that is shown is that one cannot speak of virtue using the theoretical model.

${ }^{22}$ We are again pointing here to what we have characterized as the Platonic conviction that the theoretical model is inappropriate to the "science of human affairs" and thereby call into question the eliminativist positivism of, for example, the early Wittgenstein who concludes his early masterpiece with the famous asseveration: "What we cannot speak about we must pass over in silence." (Wittgenstein 1974, 74) What we are trying to suggest, conversely, is that it is not so much that we cannot speak about ethical issues, rather, when treating of ethical issues, we should not try to use the language of logic, as delineated by Wittgenstein for example. The reductionist language of logical exactitude cannot properly account for our ethical lives and so Wittgenstein recommends that we pass over ethics in silence. The sign language of Wittgenstein's logic is an abstraction from ordinary language with a philosophically purgative application. It is not, however, the only language with which we can deal with the world.
} 
laboratory, but that language really only goes so far when it comes to the range of things we wish to discuss regarding a symphony. Granted, the non-technical languages we use might well be overly sentimental and susceptible to misuse, but that is no argument in favour of using a language which was never appropriate for the subjects we are trying to discuss in the first place. The eliminative approach then is both insidious and erroneous; it suggests that because we can document countless notorious cases where human intransigence or intellectual indigence or attachment to folk psychology or bad science impeded intellectual and scientific breakthroughs, that any resistance to a new proposal is ipso facto flawed. What is overlooked by this type of criticism is the possibility that we might refuse to make something obsolete on the basis of a new proposal because it has less explanatory success than the old model; being more recent surely does not necessarily betoken more successful or accurate. Enframing dupes people into the belief that the technical language of the exact sciences must be adopted at the expense of all other languages. Yet nowhere is it demonstrated that there is one language appropriate to human experience or life at the expense of every other mode of discourse and that it is the language of science or mathematics. And, if that much is not conceded, then the high-ground that the eliminativist claims to stand on would seem to suddenly sink to the level of one among many interpretive molehills on a vast plain of experience.

Lest we be misinterpreted here, these are not the concerns of a thoroughgoing traditionalist or sentimentalist. We are not advocating a world stripped of the scientific description. Much of what we have achieved in science and technology has made the world we live in and the lives we lead wonderful. But there are limits to what we can deem improvements. Not everything in our lives today seems to be an improvement and not because what we can avail of is per se bad, but because we live in a world where we seem forced to relinquish so much of our lives to a technological existence that we do not have a free relation to. Our relationship to technology is not what Heidegger would call a free one, one where we have the capacity to be "released" to things and take or leave technology as people who are not constrained to revealing the world for ourselves and others through a technological lens. The point is not to try and overcome or surmount technology; that was not and never will be possible. The point is to not be so enslaved to it as to think that the way it renders the world and we who live in it is the only way that we can relate to or understand ourselves, others and the world around us. The challenge still remains then for the posthumanist to try and see how much of what they advocate is merely the expression of a burgeoning and eliminative technological interpretive scheme which feeds exponentially on its own momentum and how much can justifiably be classed as reflective measures which we might think of using technology for.

On the one hand, we seem to intuitively go along with progress in medicine and so on, that is, the rate of progress when it comes to life-enhancement is something that society seems to be able to keep up with. The question is whether or not the progress being touted by the posthumanist is progress of this kind? It is certainly not necessarily the case! No one, to my knowledge, ever objected to someone receiving cancer treatment using the best methods and procedures available. The question is 
again as to whether or not there is a difference in kind between such measures and the technologies being touted for cognitive and physical enhancement and the answer to that question is neither as necessary nor obvious as the posthumanist suggests. All we can seem to do is point to the fact that for some reason, the technological stranglehold that currently grips our attitudes and understanding seems to be forcing us to contend with and accept radical shifts at an ever increasing rate. Moreover, we have to ask ourselves whether or not it is becoming increasingly difficult to make distinctions in this regard because of our improved understanding or because of a constriction of the discursive parameters involved. Many of the working assumptions concerning the meaning of the word technology reduce to what Heidegger describes as the instrumental, anthropological definition. (Heidegger 1977, 4-5) Technology then is simply understood as something that we (human beings) use instrumentally in order to further various ends. Heidegger wants to undermine this interpretation completely. Indeed, by the time one has wrapped one's head around his discussion of technology and its "essence" (Enframing), one might be forgiven for supposing that Heidegger would reverse things, that is, rather than we/human beings using technology, he might argue instead that technology uses us. And preposterous as that may sound prima facie, it is not, in the end, a million miles from the truth once one gets at what Heidegger really means by being human and what technology and, in particular, the essence of technology are manifestations of. Heidegger, as it turns out, has no desire to demonize technology, indeed, he famously proclaims in "The Question Concerning Technology" that "There is no demonry of technology". (Heidegger 1977, 28) Heidegger is not looking for some reactionary countermovement to technology nor does he think we can live our lives stripped of technology; to advocate such a move is to misunderstand the role of technology with respect to our lives and how we understand our existence and the world around us.

Heidegger might well concede that the lines have become blurred between earlier and later technologies! But far from this being something that Heidegger was enthused by or celebrated, this is something he perceived with some trepidation. Given the eliminativist bent of the technological frame of reference, everything we describe can be reduced to expressions of more and less sophisticated examples of technology. However, this is perhaps not so much because there are no differences, but because we have expunged our capacity to make any such distinctions. We no longer seem to allow for any narratives/interpretations to mean anything substantive in the language of human progress beyond the eliminativist language of technological Enframing where everything is reduced to resource and standing-reserve - to be manipulated, broken down, and either made obsolete, maintained or indeed enhanced!

\section{CONCLUSION}

In looking at our vague, quotidian sense of personhood, we managed to identify the notion of affectivity as fundamental. Any legitimate conception of personhood entails a rich emotional life, one which we can empathize with and share. Our emotional life, our affective understanding, in short, our ability to experience, according to 
Heidegger, is run through with a temporal character. That is, the manner in which any kind of experience can occur for us must be temporally filtered. Our radical finitude is constitutive, even at the subliminal level, of the way we experience, interpret and respond to the world we find ourselves thrown into. The technical approach to personhood tends to take an anatomical view of the person/human being and thus misses the narrative glue which holds the person together, namely, our historicity our temporal limits. The tendency is to look at the various components outside of any such context and to simply apply the criteria of optimum functioning. This failure to pay any attention to the temporal glue that holds our narrative, affective identities together is a critical one for the posthumanist position. Moreover, as part of that reductionist view of the human being, the posthumanist unquestioningly advocates the ideal of life extension to the nth degree, that is, their ultimate aspiration involves the vanquishing of our temporality altogether - the ultimate fantasy of corporeal and egocentric immortality. However, to achieve as much would essentially render our current sense of being human, our affectivity, our values, in short, the way we interpret and experience the world, obsolete. In other words, the ultimate aspirations and goals of posthumanism would result in the complete debasement and erasure of any current sense of humanity/personhood.

Much of what we have been trying to argue here might be dismissed as a kind of intellectual provincialism, but that is not at all the aim of this inquiry. We have no normative agenda, nor are we trying to preserve an ideal of human existence which stands as the backdrop to some kind of moral ideology. Rather, what we have been trying to suggest is that whatever way one wants to look at things, the question as to the temporal backdrop to our personhood is something that needs to be addressed. And before we can begin to consider the details of the posthumanist's position and the kinds of enhancements of cognitive and physical capacities that they discuss, we have to ask where our sense of personhood, value, or identity will come from in an age where we have gone beyond humans to posthumans. We must push the posthumanist for some further clarification as to where their criteria for evaluating enhancement come from. ${ }^{23}$ What conception of humanity or posthumanity, with overused but under-defined attendant phrases like "human dignity" and "human nature", do they in fact have? In other words, we must ask how much of their own vision and programme for improvement is a symptom of the holding sway of Enframing. How much of what they currently recommend is actually an expression of their own unquestioned acceptance of an eliminative technical interpretive scheme which currently holds sway at the expense of any other form of interpretation or understanding vis a vis human beings?

It is not so much that these concerns demonstrate the moral turpitude of posthumanism. The concern of this paper is more epistemological than normative.

23 Needless to say, reductionist, pseudo-scientific iterations like the following definition of enhancement do little substantive work, instead they reflect the reductionist interpretive prejudices of the author: "Enhancement: An intervention that improves the functioning of some subsystem of an organism beyond its reference state; or that creates an entirely new functioning or subsystem that the organism previously lacked.” (Bostrom 2008, 7) 
Indeed, the posthumanist might well riposte that the fact that our current sense of personhood has a temporal character is no argument for proposing that it ought to be this way. In the same way that we criticized an implicit version of a will/ought fallacy in the posthumanist defence of various measures they call for, we can hardly defend a status quo stance on the basis of an is/ought argument. The fact that our values and our sense of identity are currently conditioned by our temporal limits, does not mean that they must always be so conditioned. But with this, we are on the threshold of some very difficult questions; questions which posthumanists have thus far failed to identify, never mind answer. And, this is where the continental and analytic commentators need to pool their resources in the interests of moving forward. The analyst cannot resist the deconstructionist's critique without making a number of presuppositions which are not philosophically viable, not least, the supposition that it is unproblematic to proceed with an account as to what is preferable in terms of being a person, whether human or posthuman, without ever actually offering even a minimally defensible account of personhood which, for the time being, still requires an acknowledgement of the temporal constitution of identity/personhood. Nevertheless, we must still be willing to offer something substantive following the deconstructive critique; these issues, as Bostrom has convincingly argued, do and will continue to affect us all and we must develop the philosophical resources to begin to deal with them adequately. This may well be where some direction or guidance could be found in traditions outside of our own somewhat self-absorbed Western, technocentric tradition; and, while the positive possibilities seem more than encouraging, they also belong to a project to which we could pay only the most paltry lip service here and must therefore be left to future endeavours.

\section{ACKNOWLEDGEMENTS}

I am grateful to Brendan O' Mahony for commenting on an earlier draft of this paper; his criticisms and comments were hugely beneficial. I would also like to thank Brian Fitzgerald and Dermot Moran for helpful feedback and advice. Finally, I wish to thank the two anonymous reviewers of Comparative Philosophy whose penetrating criticisms and suggestions significantly improved the article.

\section{REFERENCES}

Adams, Stephen (February 13 $3^{\text {th }}, 2009$ ), "Judge takes 12,000 words to define a tree", Telegraph: <http://www.telegraph.co.uk/news/uknews/law-and-order/4613654/ Judge-takes-12000-words-to-define-a-tree.html $>$

Badmington, Neil (Winter, 2003), "Theorizing Posthumanism", Cultural Critique, No. 53 (topic: "Posthumanism"): 10-27.

Benson, Hugh H. (1990), “"Meno,' the Slave Boy and the Elenchos”, Phronesis, 25 (2): $128-58$. 
Bostrom, Nick (2005), "In Defence of Posthuman Dignity", Bioethics, 19 (3): 202-14. Bostrom, Nick (Complete draft circulated 2007), "The Future of Humanity", <http://www.nickbostrom.com/papers/future.pdf $>$

Bostrom, Nick (2008), "Dignity and Enhancement", in Human Dignity and Bioethics: Essays Commissioned by the President's Council on Bioethics (pp. 173-207). President's Council on Bioethics: Washington, D.C.: 2008. <http:// www.fhi.ox.ac.uk/_data/assets/pdf_file/0009/10224/dignity-enhancement.pdf $>$.

Bostrom, Nick and Roache, Rebecca (2007), "Ethical Issues in Human Enhancement": <http://www.nickbostrom.com/ethics/human-enhancement.pdf>

Carman, Taylor (2003), Heidegger's Analytic: Interpretation, Discourse, and Authenticity in Being and Time (New York: Cambridge University Press).

English, Jane (October 1975), "Abortion and the Concept of a Person", Canadian Journal of Philosophy, 5 (2): 233-43.

Gadamer, Hans-Georg (2003), A Century of Philosophy: a conversation with Riccardo Dottori, translated by Rod Coltman with Sigrid Koepke (New York/London: Continuum).

Hayles, N. Katherine (1999), How We Became Posthuman: Virtual Bodies in Cybernetics, Literature, and Informatics (Chicago: University of Chicago Press).

Heidegger, Martin (1962), Being and Time, translated by John Macquarrie and Edward Robinson (Oxford: Blackwell).

---- (1977), The Question Concerning Technology and other essays, translated by William Lovitt (New York: Harper \& Row).

---- (1998), "Letter on Humanism" (translated by Frank Capruzzi), in Pathmarks, edited by William McNeill (Cambridge: Cambridge University Press).

---- (1999), Contributions to Philosophy (From Enowning), translated by Parvis Emad and Kennath Maly (Bloomington \& Indianapolis: Indiana University Press).

---- (2000), Introduction to Metaphysics, translated by Gregory Fried and Richard Polt (New Haven and London: Yale University Press).

---- (2008), Letters to His Wife: 1915-1970, selected, edited and annotated by Gertrud Heidegger; translated by R.D.V. Glasgow (Cambridge: Polity Press).

McCormick, Jack (1972), "Tree" in Collier's Encyclopedia vol 22 (Crowell-Collier Educational Corporation), 448-63.

Mill, John Stuart (1991), On Utilitarianism, in On Liberty and other essays (Oxford: Oxford University Press).

Plato (2002), Meno. In Five Dialogues: Euthyphro, Apology, Crito, Meno, Phaedo, translated by G.M.A. Grube (Indianapolis: Hacket).

Nietzsche, Friedrich (November 14, 1881), "Letter to Franz Overbeck": <http://www.thenietzschechannel.com>.

Roochnik, David (1996), Of Art and Wisdom: Plato's Understanding of Techne (University Park, PA: The Pennsylvania State University Press).

Sandberg, Anders and Bostrom, Nick (2006) "Converging Cognitive Enhancements": <http://www.nickbostrom.com/papers/converging.pdf > .

Sapontzis, S.F. (Jul., 1981), “A Critique of Personhood”. Ethics, 91 (4): 607-18. 
Schechtman, Mayra (Feb., 1990), "Personhood and Personal Identity", The Journal of Philosophy, 87 (2): 71-92.

Sontag, Frederick (Oct. 1967), "Heidegger, Time, and God", The Journal of Religion, 47 (4): 279-94.

Williams, Bernard (1993), Ethics and the Limits of Philosophy (London: Fontana Press).

Wittgenstein, Ludwig (1974), Tractatus Logico-Philosophicus; translated by D.F. Pears and B.F. McGuinness (London and New York: Routledge). 